\title{
The anatomical suitability of C1-2 transarticular screw placement in pediatric patients
}

\author{
Douglas L. Brockmeyer, M.D., Julie E. York, M.D., and Ronald I. Apfelbaum, M.D., \\ Division of Pediatric Neurosurgery, Primary Children's Medical Center, and Department of \\ Neurosurgery, University of Utah, Salt Lake City, Utah
}

Craniovertebral instability is a challenging problem in pediatric spinal surgery. Recently, C1-2 transarticular screw fixation in pediatric patients has been used to assist in the stabilization of the craniovertebral joint. Currently there are no data that define the anatomical suitability of this technique in the pediatric population. The authors report their experience in 32 pediatric patients in whom craniovertebral instability was treated by placement of C1-2 transarticular screws.

From March 1991 to October 1998, 32 patients 16 years of age or younger with atlantooccipital, or atlantoaxial instability, or both were evaluated at our institution. There were 22 boys and 10 girls. Their ages ranged from 4 to 16 years (mean age 10.2 years). The most common causes of instability were os odontoideum (12 patients) and ligamentous laxity (nine patients). Six patients had undergone a total of nine previous attempts at posterior fusion at outside institutions.

All patients underwent extensive preoperative radiological evaluation including thin cut (1-mm) computerized tomography scanning with multiplanar reconstruction to evaluate the $\mathrm{C} 1-2$ joint space anatomy. Of the 64 possible $\mathrm{C} 1-2$ joint spaces in 32 patients, 55 sides $(86 \%)$ were considered suitable for transarticular screw placement preoperatively. In three patients the C1-2 joint space anatomy was considered unsuitable for screw placement bilaterally. In three patients the anatomy was considered inadequate on one side. Fifty-five C1-2 transarticular screws were subsequently placed, with no resulting neurological or vascular complications. We conclude that $\mathrm{C} 1-2$ transarticular screw fixation is technically possible in a large proportion of pediatric patients with craniovertebral instability.

Key Words * pediatrics * transarticular screw * craniovertebral junction * occipitalcervical instability * atlantoaxial instability

The management of craniovertebral instability by performing C1-2 transarticular screw fixation has achieved a high degree of acceptance and success in adult patients. The main reasons for the rapid acceptance of this technique are high fusion rates and a relatively low incidence of complications.[1,4-8,10-13,16-18] In a report by Paramore, et al.,[14] the anatomic suitability of C1-2 joint spaces for transarticular screw fixation in adult patients was examined. They reviewed a series of 
computerized tomography (CT) scans obtained in surgically and nonsurgically treated patients to determine the potential for $\mathrm{C} 1-2$ screw placement. In addition, they described a method for determining a potential screw trajectory. They concluded that 18 to $23 \%$ of patients "may not be suitable for posterior C1-2 transarticular screw fixation on at least one side." Although that report is helpful as a reference, it cannot be applied directly to the pediatric population without first discussing the unique anatomy of the developing craniovertebral junction and accounting for the challenges presented by congenital vertebral anomalies.

In a recently published case series in which upper cervical fusion procedures in pediatric patients were discussed, the authors stated that C1-2 transarticular screw fixation is "often not applicable to preadolescent children."[9] They believed that young children may lack adequate bone thickness for good screw purchase. Although we agree that both the smaller size constraints and the tendency toward congenital or syndromic bony abnormalities make the pediatric population a challenge to manage, we disagree that transarticular screws cannot be used in pediatric spinal surgery. We report our experience in evaluating 32 children with instability at the atlantooccipital level, atlantoaxial level, or both levels with regard to the anatomical suitability of C1-2 transarticular screw fixation, and we discuss our approach to determining whether or not transarticular screw placement is appropriate in a given patient.

\section{CLINICAL MATERIALS AND METHODS}

From March 1, 1991 to October 1, 1998, 32 consecutive patients 16 years of age or younger with atlantooccipital, atlantoaxial, or occipitoatlantoaxial instability were evaluated at Primary Children's Medical Center or The University of Utah Medical Center in Salt Lake City, Utah. A retrospective review of the patients' medical records was undertaken, and each patient was characterized by age, sex, cause and level of instability, and treatment type.

All patients underwent extensive preoperative imaging, including plain radiography, CT scanning, and magnetic resonance imaging. A standard format for CT scanning was followed throughout. The format called for thin-cut $(1 \mathrm{~mm})$ CT slices to be obtained from the occiput to C-3 so that the entire potential transarticular screw trajectory could be visualized. Preoperatively each patient's radiological data were carefully assessed to determine the suitability of each C1-2 joint to accept a transarticular screw. Joints were considered not to be suitable for screw placement if the location of the $\mathrm{C}-2$ transverse foramen precluded screw placement, or if there was inadequate bone to accept at least a $3.5 \mathrm{~mm}$-diameter screw along the entire proposed pathway.

The process of establishing a safe C1-2 transarticular screw trajectory by using thin-cut CT reconstruction requires intimate knowledge of the patient's atlantoaxial anatomy. One technique is to use a high-speed CT work station when performing the planning. First, a two-dimensional parasagittal reconstruction of the atlantoaxial joint is created to identify the transarticular screw entry point near the C2-3 facet joint on one side (Fig. 1). 


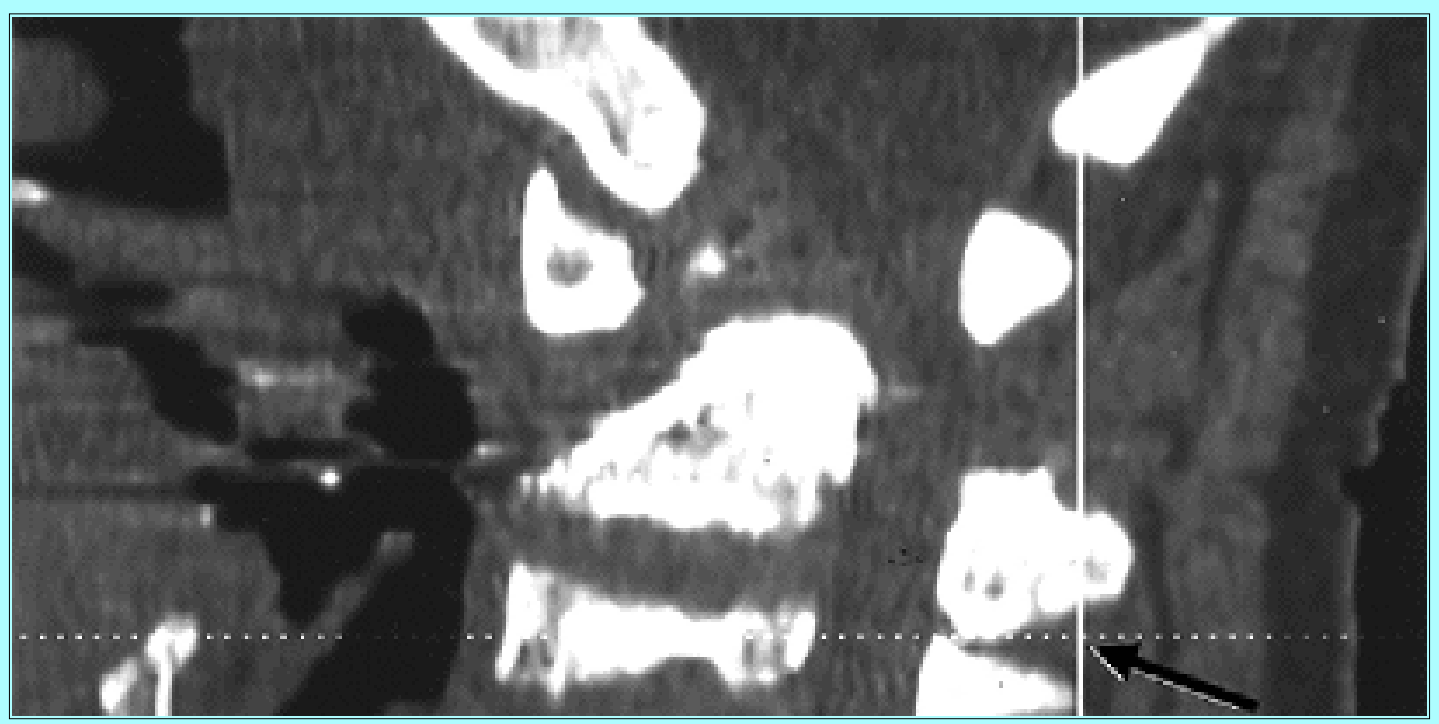

Fig. 1. Parasagittal CT reconstruction with the cursor placed near the midpoint of the C2-3 facet joint on one side. The arrow identifies the "trajectory origin" (see text).

This screw entry point will be referred to as the "trajectory origin." Second, an axial slice obtained through the C-2 pars interarticularis is produced, and with the trajectory origin still at the midpoint of the C2-3 facet, the screw trajectory is chosen by angling the plane of reconstruction slightly medial $\left(2-5^{\circ}\right)$ to the parasagittal plane (Fig. 2 upper). We then produce a reconstructed image, slightly off the parasagittal plane, which is the first approximation of the anticipated screw trajectory (Fig. 2 lower). Third, in a systematic fashion, the screw trajectory is adjusted both medially and laterally on the axial images to determine the greatest amount of bone available for transarticular screw purchase. Finally, the second and third steps are repeated at least two more times, once with the trajectory origin just medial to the midpoint of the C2-3 facet joint and once just lateral. This entire process is then repeated on the opposite side. 


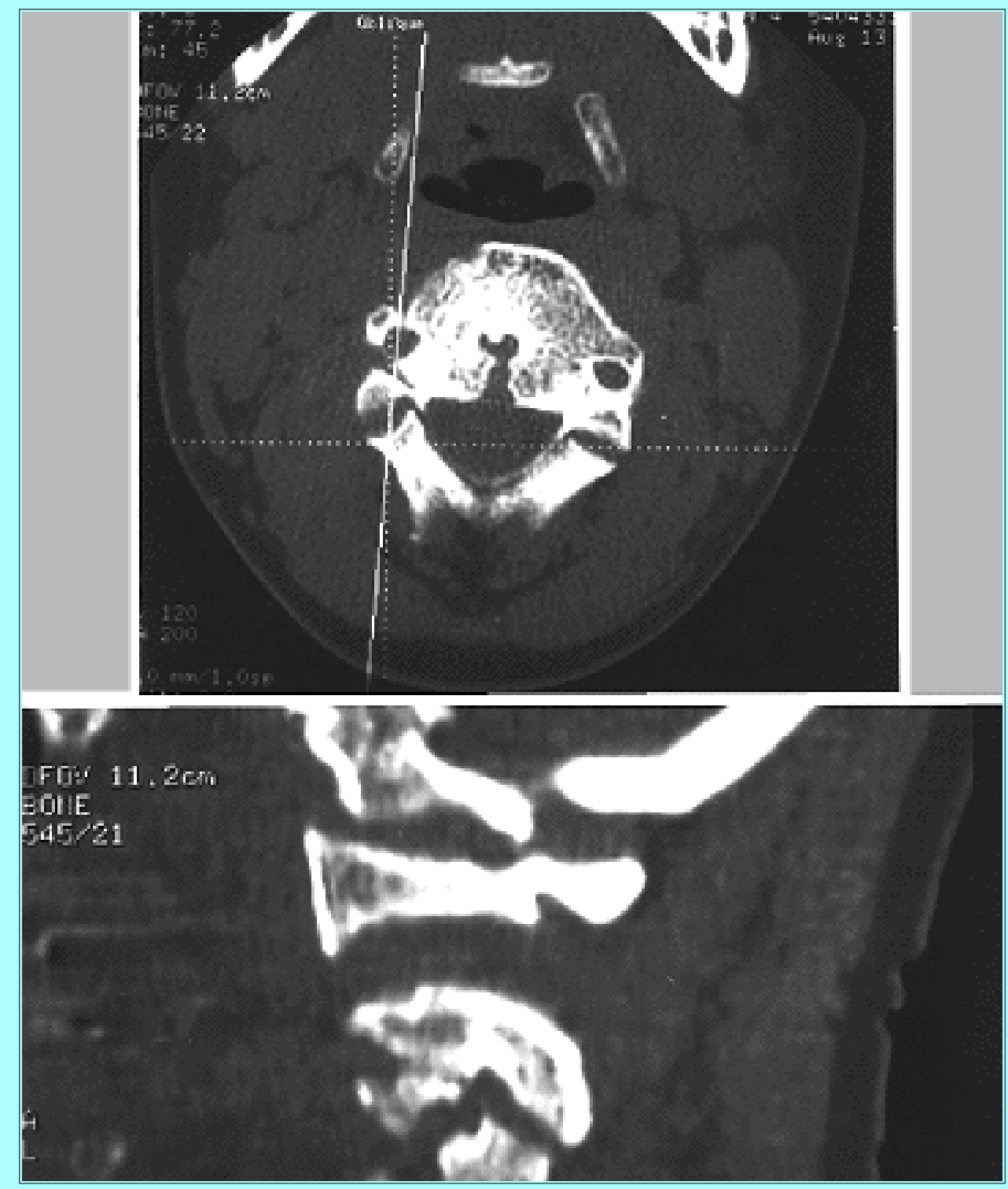

Fig. 2. Upper: Axial image CT scan revealing the screw trajectory (solid line) angled slightly medial to the parasagittal plane. Lower: Parasagittal CT reconstruction produces along the screw trajectory showing adequate available bone for good screw purchase.

The final trajectory of the screw traverses a portion of the $\mathrm{C}-2$ pedicle, $\mathrm{C}-2$ pars interarticularis, $\mathrm{C} 1-2$ joint space, and lateral mass of C-1. All of these structures should be visualized on the reconstructed image, with the trajectory often times just off the true parasagittal plane. The final result of this analysis is a screw trajectory that utilizes the maximum amount of atlantoaxial bone available. We believe this systematic approach allows a high degree of flexibility during the preoperative planning stage, especially for small patients or those in whom bony anomalies are present.

\section{RESULTS}

Overall characteristics of the patients are summarized in Table 1. Patient age ranged from 4 to 16 years, with a mean age of 10.2 years. There were 22 boys and 10 girls. The most common causes of craniocervical instability were os odontoideum (12 patients) and ligamentous laxity (nine patients). Associated causes included trauma in 10 patients and Down's syndrome (trisomy 21) in six patients. Atlantoaxial instability was demonstrated in 17 patients, occipitalcervical junction instability in 11 and both atlantooccipital and atlantoaxial instability in four. At outside institutions six patients had undergone 
a total of nine previous attempts at posterior fusion.

\begin{tabular}{|c|c|c|c|c|c|}
\hline & & WMARY OF DIAGNOS B, & $\begin{array}{c}\text { TABLE } 1 \\
\text { USE OF INSTABLITV, AND T } \\
32 \text { PED KTRIC PATIENTS }\end{array}$ & E OF INSTRUMENTATION IN & \\
\hline $\begin{array}{l}\text { Case } \\
\text { No. }\end{array}$ & $\begin{array}{l}\text { Age } \\
{\left[y^{\circ} s\right]}\end{array}$ & Diagnosis & Cause of Instability & $\begin{array}{l}\text { Irstrumentation } \\
\text { (no. of screws] }\end{array}$ & $\begin{array}{l}\text { Screw } \\
\text { Length } \\
\text { (m m) }\end{array}$ \\
\hline 1 & 4 & metatrophic duarfism & os odontoideum & c1-2 screms (2) & 38,38 \\
\hline$\frac{2}{3+}$ & 6 & trauma & os odontoideum & C1-2 screns (2) & 34,34 \\
\hline $3 \dagger$ & 6 & failed fusion & os odontoideum & c1-2 screms (2) & 32,36 \\
\hline $4 \dagger$ & 6 & failed fusion ( 3 ops) & os odontoideum & c1-2 screms (2) & 30,30 \\
\hline 5 & 6 & rotatory subluxation & hypoplastic dens & c1-2 screms (2) & 36,36 \\
\hline 6 & 6 & trauma & Type II odontoid fracture & sublaminar tycron & none \\
\hline 7 & 10 & Down's syndrome & os odontoideum & c1-2 screms (2) & 30,30 \\
\hline 8 & 11 & trauma & hypoplastic dens & c1-2 screms (2) & 32,32 \\
\hline 9 & 12 & Down's syndrome & os odontoideum & c1-2 screns (2) & 32,32 \\
\hline 10 & 13 & trauma & os odontoideum & c1-2 screns (2) & 38,40 \\
\hline $11 \dagger$ & 14 & failed fusion & os odontoideum & c1-2 screws (2) & 38,38 \\
\hline 12 & 14 & trauma & os odontoideum & c1-2 screms (2) & 36,36 \\
\hline 13 & 14 & trauma & Type II odontoid fracture & c1-2 screms (2) & 42,44 \\
\hline $14 \dagger$ & 15 & fajled fusion & Type II odontoid fracture & c1-2 screns (2) & 44,46 \\
\hline $15 \dagger$ & 15 & failed fusion & os odontoideum & c1-2 screms (2) & 40,46 \\
\hline 16 & 16 & trauma & os odontoideum & c1-2 screns (2) & 48,48 \\
\hline $17 \dagger$ & 16 & failed fusion (2 ops) & Type II odontoid fracture & c1-2 screns (2) & 38,42 \\
\hline 18 & 4 & congenital instatility & ligamen tous laxity & Uloop, c1-2 sorems (2) & 34,34 \\
\hline 19 & 4 & Down's syndrome & $\begin{array}{l}\text { os odontoideum, } \\
\text { ligamen tous laxity }\end{array}$ & Uloop, c1-2 screms (2) & 36,36 \\
\hline 20 & 5 & trauma & ligamen tous disruption & Uloop, C1-2 screms (2) & 38,38 \\
\hline 21 & 5 & Doun's syndrome & ligamen tous laxity & Uloop, c1-2 screms (2) & 32,34 \\
\hline 22 & 5 & Klippel-Feil syndrome & $\begin{array}{l}\text { transoral odontoid } \\
\text { resection }\end{array}$ & Steinman pin w/cables & none \\
\hline 23 & 6 & Doun's syndrome & ligamen tous laxity & Uloop, C1-2 screms (2) & 30,32 \\
\hline 24 & 6 & osteom yelitis & $\begin{array}{l}\text { transoral odontoid } \\
\text { resection }\end{array}$ & Uloop, c1-2 sorew (1) & \\
\hline 25 & 13 & trauma & ligamen tous laxity & Uloop, C1-2 screms (2) & 32,32 \\
\hline 26 & 13 & Doun's syndrome & ligamen tous laxity & Uloop, c1-2 screms (2) & 42,44 \\
\hline 27 & 13 & trauma & ligamen tous disruption & U loop, C1-2 screms (2) & 38,40 \\
\hline 28 & 13 & Down's syndrome & ligamen tous laxity & Uloop, C1-2 screw (1) & 36 \\
\hline 29 & 14 & congenital instatility & ligamen tous laxity & Uloop, c1-2 sorew (1) & 40 \\
\hline 30 & 16 & $\begin{array}{l}\text { cervicomedullary } \\
\text { compression }\end{array}$ & $\begin{array}{l}\text { transoral odontoid } \\
\text { resection }\end{array}$ & Uloop, C1-2 screms (2) & 48,48 \\
\hline 31 & 16 & cranial settling & PFD, $\mathrm{c}-1$ laminectom $y$ & Uloop, c1-2 screms (2) & 36,36 \\
\hline 32 & 13 & Morquio's disease & ligamen tous laxity & Uloop, sublaminar cables & none \\
\hline
\end{tabular}

After careful assessment of the preoperative multiplanar CT reconstructions, we judged that the anatomy in $55(86 \%)$ of $64 \mathrm{C} 1-2$ joint spaces, including the position of the vertebral artery, and the anatomical relationship of C-1 to C-2 was suitable for transarticular screw placement. Overall, 29 of 32 patients (91\%) underwent C1-2 transarticular screw fixation. In three patients there was unsuitable anatomy bilaterally, and in another three patients there was unsuitable anatomy unilaterally. For those patients in whom the anatomy was judged suitable for screw placement, the screw diameter was chosen after careful examination of the CT scan. All joint spaces accepted either a 3.5- or 4-mm-diameter screw, except for one in which we placed a 2.7-mm-diameter screw. In patients with occipitocervical instability in whom C1-2 screws were placed stabilization was achieved with a contoured occipitocervical U loop that was modified to incorporate $\mathrm{C} 1-2$ transarticular screws. All constructs were supplemented with autologous 
iliac crest bone graft and multistranded cable.

There were no vertebral artery or neural element injuries during placement of any of the 55 transarticular screws. Figure 3 demonstrates postoperative images of two representative cases.

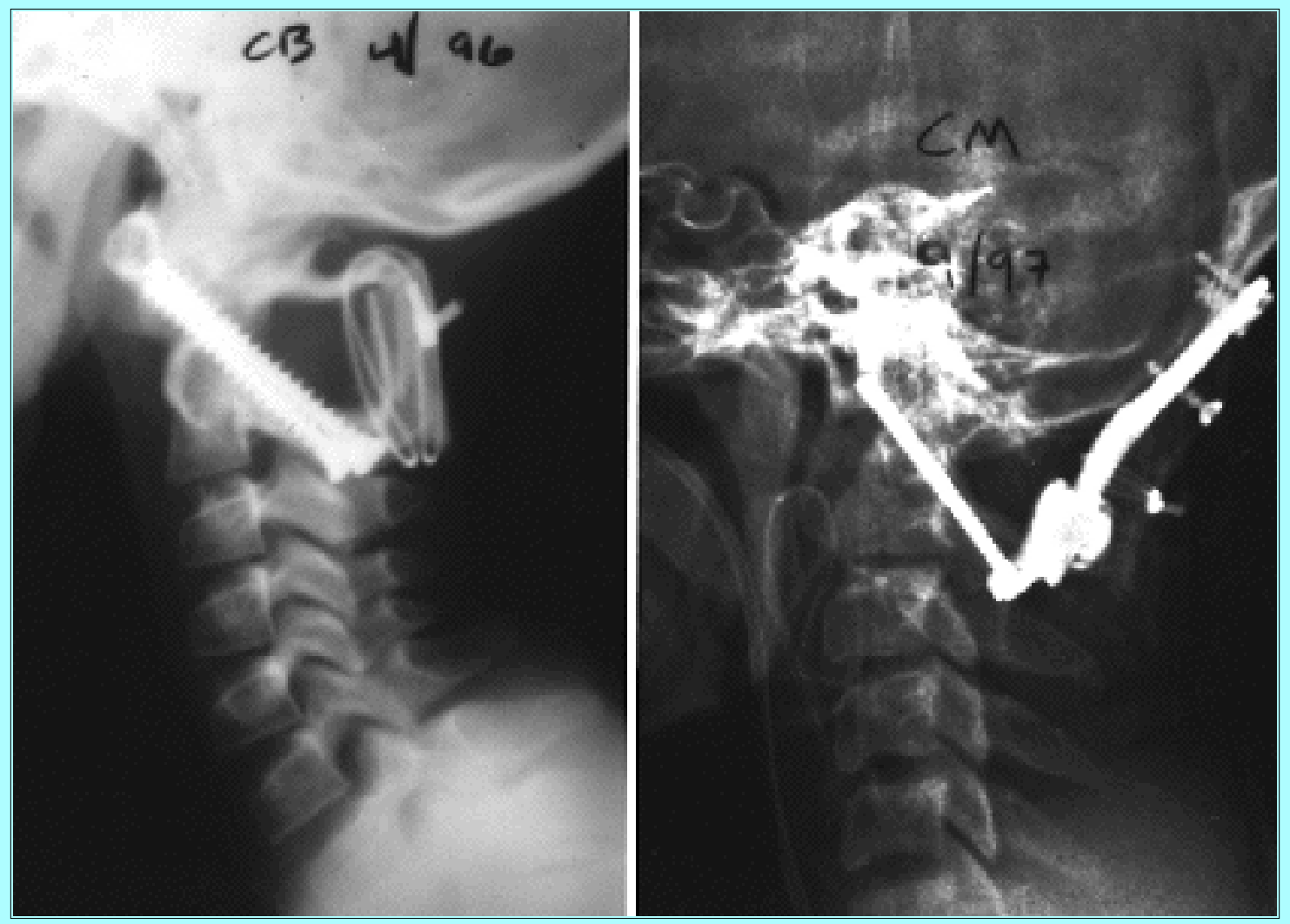

Fig. 3. Postoperative lateral plain radiographs revealing C1-2 transarticular screw fixation for the management of atlantoaxial instability (left) and occipitoatlantoaxial instability (right).

\section{DISCUSSION}

We have demonstrated that C1-2 transarticular screw placement for craniovertebral instability is feasible in a large proportion of pediatric patients. We found that in $91 \%$ of pediatric patients there was at least one C1-2 joint that was considered anatomically suitable for C1-2 transarticular screw placement. Overall, $86 \%$ of all potential joint spaces were considered suitable. Transarticular screws were then safely and successfully placed in all of the C1-2 joint spaces that had been judged anatomically suitable preoperatively.

Previous work by several authors has defined the safety and efficacy of this procedure in adult patients. $[4,5,10,13,16,18]$ Notable among these series is the work by Paramore, et al.,[14] who reported that in 18 to $23 \%$ of a general population of adult patients the C1-2 anatomy might not be suitable for placement of transarticular screws on at least one side.

In the only published report of the application of this technique in pediatric cases, Brockmeyer, et al.,[3] described its use in two patients, aged 6 and 10 years. Lowry, et al.,[9] reviewed the outcomes of 25 pediatric patients who underwent fusion for occipitocervical or upper cervical spine instability by conventional means. The mean age of children in their series was 9 years. Diagnoses were similar between the series reported by Lowry, et al., and our present series, with the majority of children having 
atlantoaxial instability associated with os odontoideum or congenital atlantoaxial hypermobility. Although they discussed the potential application of C1-2 transarticular screw placement in their patients, the technique was not utilized.

Potential concerns about performing transarticular screw placement in children have previously been discussed in our earlier case series.[3] These concerns include the potential for limiting future growth, the development of juxtafusion disease, and the youngest age for which this procedure may be performed. Because a child's craniovertebral region reaches adult size and configuration by approximately age 8 to 10 years, the potential for significant growth limitation is minimal. $[2,15]$ In our experience, this procedure can probably consistently be performed at 4 or 5 years of age, although we know of one 3-year-old patient in whom this procedure was performed. (Weidner, personal communication, 1993) Long-term follow-up review is required to determine if there are any developmental complications related to screw fixation in this group of pediatric patients.

Thorough preoperative imaging and analysis of the craniovertebral junction is of paramount importance before considering C1-2 transarticular screw placement in a pediatric patient. The screw trajectory reconstruction algorithm that we employed enabled a flexible approach to preoperative planning and facilitated the definition of a safe screw trajectory in the maximum number of patients. In contrast with other described methods, our method provides for the flexibility of choosing a pathway that is angled off a strictly coronal or sagittal plane. On a number of occasions, we found that the optimum trajectory was directed slightly medially within the pars interarticularis. Without this additional flexibility, it is unlikely that we would have been confident enough to place screws in as many patients as we did.

In summary, we have demonstrated that in the great majority of pediatric patients who present with instability of the craniovertebral junction, favorable anatomy and adequate bone thickness are present for the safe and successful placement of C1-2 transarticular screws.

\section{References}

1. Apfelbaum R: Posterior transarticular C1-2 screw fixation for atlantoaxial instability. Aesculap Scientif Inform 25:1-4, 1994

2. Bailey D: The normal cervical spine in infants and children. Radiology 69:712-719, 1952

3. Brockmeyer D, Apfelbaum R, Tippets R, et al: Pediatric cervical spine instrumentation using screw fixation. Pediatr Neurosurg 22:147-157, 1995

4. Dickman CA, Sonntag VKH: Posterior C1-C2 transarticular screw fixation for atlantoaxial arthrodesis. Neurosurgery 43:275-281, 1998

5. Gebhard JS, Schimmer RC, Jeanneret B: Safety and accuracy of transarticular screw fixation C1-C2 using an aiming device. An anatomic study. Spine 23:2185-2189, 1998

6. Grob D, Crico JJ III, Panjabi MM, et al: Biomechanical evaluation of four different posterior atlantoaxial fixation techniques. Spine 17:480-490, 1992

7. Grob D, Jeanneret B, Aebi M, et al: Atlanto-axial fusion with transarticular screw fixation. J Bone Joint Surg (Br) 73:972-976, 1991 
8. Hanson PB, Montesano PX, Sharkey NA, et al: Anatomic and biomechanical assessment of transarticular screw fixation for atlantoaxial instability. Spine 16:1141-1145, 1991

9. Lowry DW, Pollack IF, Clyde B, et al: Upper cervical spine fusion in the pediatric population. J Neurosurg 87:671-676, 1997

10. Madawi AA, Casey ATH, Solanki GA, et al: Radiological and anatomical evaluation of the atlantoaxial transarticular screw fixation technique. J Neurosurg 86:961-968, 1997

11. Magerl F, Seemann PS: Stable posterior fusion of the atlas and axis by transarticular screw fixation, in Kehr P, Weidner A (eds): Cervical Spine I. Vienna: Springer-Verlag, 1987, pp 322-327

12. Marcotte P, Dickman CA, Sonntag VKH, et al: Posterior atlantoaxial facet screw fixation. J Neurosurg 79:234-237, 1993

13. Naderi S, Crawford NR, Song GS, et al: Biomechanical comparison of C1-C2 posterior fixations. Cable, graft, and screw combinations. Spine 23:1946-1956, 1998

14. Paramore CG, Dickman CA, Sonntag VKH: The anatomical suitability of the C1-2 complex for transarticular screw fixation. J Neurosurg 85:221-224, 1996

15. Sherk HH, Nicholson JT, Chung SM: Fractures of the odontoid process in young children. J Bone Joint Surg (Am) 60:921-924, 1978

16. Song GS, Nicholas T, Dickman CA, et al: Unilateral posterior atlantoaxial transarticular screw fixation. J Neurosurg 87:851-855, 1997

17. Stillerman CB, Wilson JA: Atlanto-axial stabilization with posterior transarticular screw fixation: technical description and report of 22 cases. Neurosurgery 32:948-955, 1993

18. Welch WC, Subach BR, Pollack IF, et al: Frameless stereotactic guidance for surgery of the upper cervical spine. Neurosurgery 40:958-964, 1997

Manuscript received April 19, 1999.

Accepted in final form May 14, 1999.

Address reprint requests to: Douglas L. Brockmeyer, M.D., Division of Pediatric Neurosurgery, Primary Children's Medical Center, 100 N. Medical Dr., Salt Lake City, Utah 84132. 